\title{
Soil Salinity Mapping of Urban Greenery Using Remote Sensing and Proximal Sensing Techniques; The Case of Veale Gardens within the Adelaide Parklands
}

\author{
Hamideh Nouri ${ }^{1, *(1)}$, Sattar Chavoshi Borujeni ${ }^{2}$, Sina Alaghmand ${ }^{3}$, Sharolyn J. Anderson 4 (D), \\ Paul C. Sutton ${ }^{4,5}$, Somayeh Parvazian 6 (1) and Simon Beecham ${ }^{7}$ \\ 1 Department of Water Engineering and Management, University of Twente, 7500 AE Enschede, The Netherlands \\ 2 Soil Conservation and Watershed Management Research Department, Isfahan Agricultural and Natural \\ Resources Research and Education Centre, AREEO, Isfahan 8174835117, Iran; chsatar@gmail.com \\ 3 Department of Civil Engineering, Monash University, 23 College Walk, Clayton, VIC 3800, Australia; \\ sina.alaghmand@monash.edu \\ 4 School of Natural and Built Environments, University of South Australia, Adelaide, SA 5095, Australia; \\ Sharolyn.Anderson@unisa.edu.au (S.J.A.); paul.sutton@unisa.edu.au (P.C.S.) \\ 5 Department of Geography and the Environment, University of Denver, Denver, CO 80208, USA \\ 6 National Centre for Vocational Education Research (NCVER), Adelaide, SA 5000, Australia; \\ Somayeh.Parvazian@ncver.edu.au \\ 7 Information Technology, Engineering and the Environment, University of South Australia, Mawson Lakes, \\ SA 5095, Australia; Simon.Beecham@unisa.edu.au \\ * Correspondence: H.Nouri@utwente.nl; Tel.: +31-534899197
}

Received: 8 June 2018; Accepted: 31 July 2018; Published: 9 August 2018

\begin{abstract}
More well-maintained green spaces leading toward sustainable, smart green cities mean that alternative water resources (e.g., wastewater) are needed to fulfill the water demand of urban greenery. These alternative resources may introduce some environmental hazards, such as salt leaching through wastewater irrigation. Despite the necessity of salinity monitoring and management in urban green spaces, most attention has been on agricultural fields. This study was defined to investigate the capability and feasibility of monitoring and predicting soil salinity using proximal sensing and remote sensing approaches. The innovation of the study lies in the fact that it is one of the first research studies to investigate soil salinity in heterogeneous urban vegetation with two approaches: proximal sensing salinity mapping using Electromagnetic-induction Meter (EM38) surveys and remote sensing using the high-resolution multispectral image of WorldView3. The possible spectral band combinations that form spectral indices were calculated using remote sensing techniques. The results from the EM38 survey were validated by testing soil samples in the laboratory. These findings were compared to remote sensing-based soil salinity indicators to examine their competence on mapping and predicting spatial variation of soil salinity in urban greenery. Several regression models were fitted; the mixed effect modeling was selected as the most appropriate to analyze data, as it takes into account the systematic observation-specific unobserved heterogeneity. Our results showed that Soil Adjusted Vegetation Index (SAVI) was the only salinity index that could be considered for predicting soil salinity in urban greenery using high-resolution images, yet further investigation is recommended.
\end{abstract}

Keywords: optical remote sensing; worldview3; EM38; urban green spaces; Adelaide parklands

\section{Introduction}

Most urban green spaces in arid and semi-arid climates such as South Australia, which are experiencing hotter and drier summers with more frequent and severe droughts, are facing critical 
challenges in maintaining and expanding their urban green spaces. Increasing urbanization and shortages in fresh water resources have resulted in introducing alternative water resources, such as reclaimed wastewater or stormwater as irrigation sources. These alternative irrigation resources, if uncontrolled, may contribute to salt accumulation and water table elevation that can cause urban soil salinity and ultimately soil and ground water degradation. In contrast, a balanced salinity management strategy decreases fertigation costs and ensures environmental protection. In the city of Adelaide, South Australia, recycled wastewater from the Glenelg to the Adelaide Parklands (GAP) scheme is the primary irrigation source for the largest public urban greenery, the Adelaide Parklands. This is an area covering approximately 720 hectares that contains a variety of soils, vegetation, and microclimates. Destructive soil sampling or leachate collection would not be a practical approach to study the salinity status in such a vast area. Quite simply, these types of field work at these large scales are expensive, particularly regarding labor, and the costs involve the leachate water quality analysis. Considering the capability, availability, and affordability of proximal sensing (near sensing) and remote sensing approaches, this research was designed to find a simple, practical, and affordable way to investigate the capability of these methods to map and model soil salinity of urban greenery.

Mapping and modeling of soil salinity are even more of a challenge in the case of non-agricultural systems, such as urban green spaces, which need to consider the heterogeneity of urban landscapes [1]. These inherent attributes together with the high spatial and temporal variability of urban soils lead to complexity in mapping soil salinity in urban greenery. Very few studies have investigated the performance of different approaches to map the soil salinity of urban landscapes.

Mapping spatio-temporal variation of soil salinity is one of the fundamental steps in salinity management. However, it is not a simple process. Measuring soil salinity is a point measurement in most field-based studies including proximal sensing approaches, and an appropriate interpolation method needs to be selected to estimate salinity values for non-sampled positions [2]. Finding a suitable interpolation method for a proximal sensing approach such as the electromagnetic tool of EM38 surveys is often not difficult [3], as the method can provide over 5000 salinity point readings in one hectare compared with destructive soil sampling or leachate collection with an average of fewer than 50 readings per hectare.

This study aims to map soil salinity from wastewater irrigation in urban parklands. To achieve this aim, the capability of high-resolution satellite images on soil salinity mapping was investigated. An extensive literature review of mapping soil salinity using remote sensing techniques showed very few studies in urban areas [4-6]. Similar studies with lower resolution images reported altered results for their analysis. As for instance, Whitney et al. [7] stated that the correlation coefficients between soil salinity and different remote sensing indices such as Normalized Difference Vegetation Index (NDVI) and the Enhanced Vegetation Index (EVI) were $r=0.644$ and $r=0.602$, respectively. Dehni et al. [8] referred to a $r=0.53$ coefficient between the salinity index and vegetation in salt-affected soil and a $r=0.48$ coefficient between Salinity Index (SI) and NDVI. Alexakis et al. [9] evaluated the feasibility of soil salinity mapping using WorldView2 (WV2) and Landsat 8 compared with in situ; they reported a wide range of correlation coefficients from 0.13 for the SAVI to 0.689 for the SI.

The novelty of this study relies on the potential application of high-resolution multispectral image of WorldView3 in urban green space. In this research, two approaches of proximal sensing and optical remote sensing were employed to map and model soil salinity in heterogeneous urban greenery. This experiment was implemented at Park 21 within the Adelaide Parklands as the experimental site.

\section{Study Area}

The city of Adelaide sits at an average elevation of $50 \mathrm{~m}$ above sea level, and Mount Lofty, with a maximum elevation of $727 \mathrm{~m}$, is the highest point of the Adelaide plain. Compared with South Australia, Adelaide's climate is known as atypical, because Mt. Lofty is the most influential topographic feature. According to the Köppen climate classification, Adelaide has a Mediterranean climate. It has hot, dry summers and mild short winters. The average temperature ranges from $13.7^{\circ} \mathrm{C}$ 
$\left(56.7^{\circ} \mathrm{F}\right)$ in August to $21.2{ }^{\circ} \mathrm{C}\left(70.2^{\circ} \mathrm{F}\right)$ in February. The Adelaide plains receive $95 \mathrm{~mm}$ and $19 \mathrm{~mm}$ monthly rainfall in winter and summer, respectively. Soils in the Adelaide region include alluvial soils, red-brown earth, and brown soil. The Adelaide Parklands are irrigated with the GAP recycled wastewater (Figure 1). Due to the heterogeneity of species, the source of irrigation, accessibility, safety, and existing research records, Park 21 was selected as the study site. The southern part of Park 21, occupying 10.5 hectares, is located between the latitudes of $34^{\circ} 56^{\prime} 8^{\prime \prime} \mathrm{S}$ and $34^{\circ} 56^{\prime} 15^{\prime \prime} \mathrm{S}$ and the longitudes of $138^{\circ} 35^{\prime} 40^{\prime \prime} \mathrm{E}$ and $138^{\circ} 36^{\prime} 1^{\prime \prime} \mathrm{E}$. It has more than 60 different species and types of landscape trees and shrubs with broad coverage of Kikuyu turf grasses [10]. This heterogeneity helps to investigate the range of soil salinity tolerance in many species. A regular soil salinity map over the years will assist in understanding the physical behavior of different species on adapting to temporal changes of salinity.
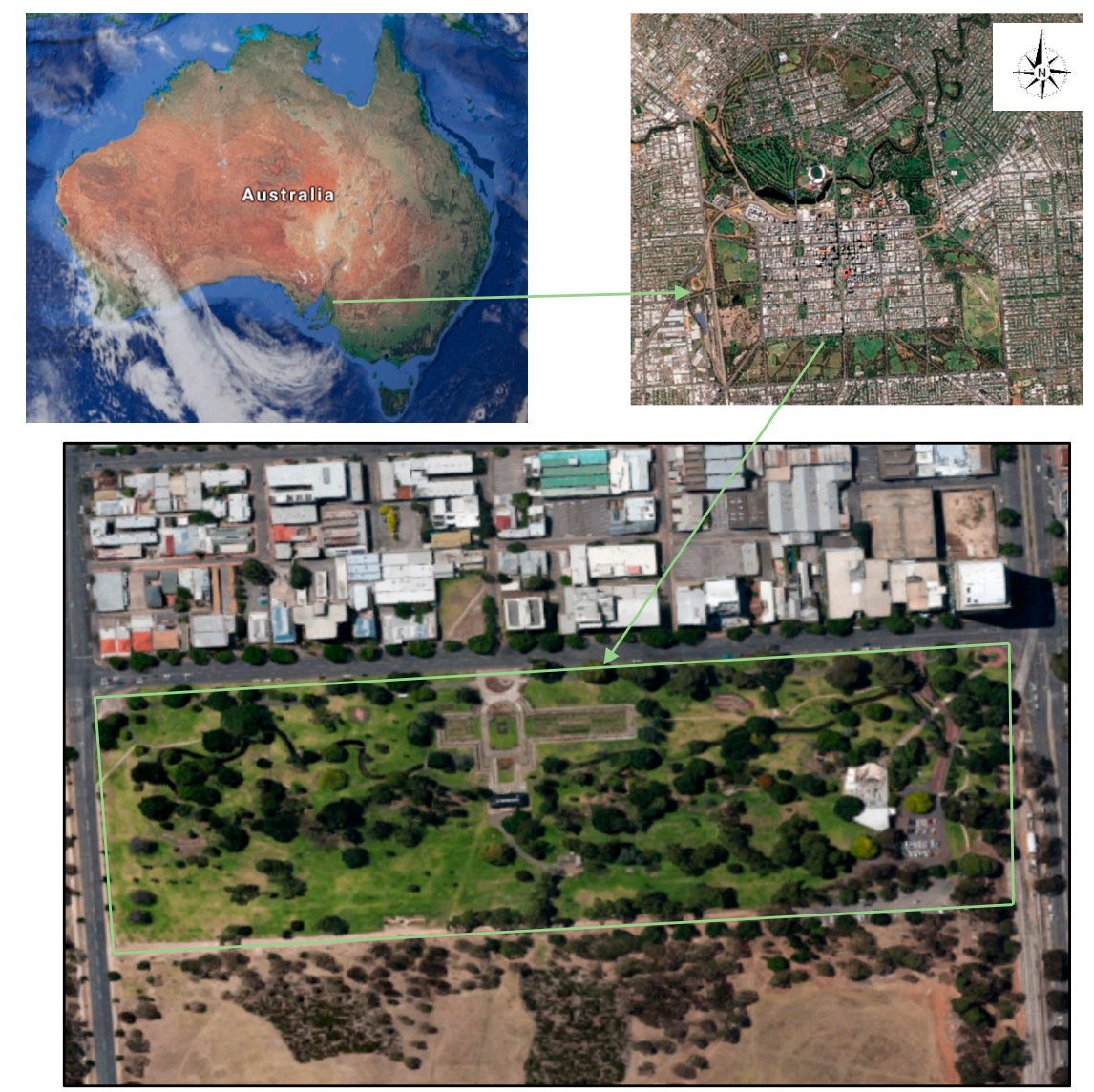

$100 \mathrm{~m}$

Figure 1. The southern part of Park 21 within the Adelaide Parklands $\left(34^{\circ} 56^{\prime} 24.5^{\prime \prime} \mathrm{S}, 138^{\circ} 36^{\prime} 08.3^{\prime \prime} \mathrm{E}\right)$.

\section{Material and Methods}

\subsection{Proximal Sensing and Laboratory}

An EM38 instrument, a data logger, and a global positioning system (GPS) were employed to collect electrical conductivity values and geographical coordinates of points in Park 21, covering 10.5 hectares of urban vegetation. A total of 52,470 observations were recorded during the survey day in rows with about 2-m distance. The adopted calibration method used spatial regression techniques to convert the EM38 readings to soil salinity [11]. Due to a common difficulty with metadata analysis for some geostatistical software, $25 \%$ of the readings were randomly selected for further analysis. The interpolation of around 1000 points over $1 \mathrm{M}$ of pixels might take several 
hours on a standard PC [12]. Negative EM38 readings were considered as outliers and were deleted from the dataset resulting in 52,096 sample points for data analysis. The statistical distribution of the data was then tested and was found to follow a normal distribution.

The data collected by EM38 is not continuous but can be mapped to create a continuous surface if a suitable method of interpolation is adopted [13-15]. Because traditional methods of soil salinity measurements are mostly point-based, labor-intensive, time-consuming, and costly, electromagnetic induction technology has spread rapidly [16-20]. This non-invasive proximal sensing technology provided a series of point measurements easily and quickly compared with traditional methods $[13,14,21]$. A set of point observations (often thousands of points) can provide a good representation of the heterogeneous nature of some soil properties in an urban green space. It can also provide a high-accuracy soil salinity map [13,22]. However, electromagnetic induction technology is site-specific and cannot entirely replace traditional methods [23]. Field or ground-truthing is still crucial to validate EM38 observations [22,24].

To create a continuous surface map of soil salinity, spatial interpolation techniques were used after data cleaning. Although there are several interpolation methods to measure non-sampled variables, previous research studies have shown that there is no single most appropriate method for the interpolation [25-28]. From two major groups of interpolation techniques, namely deterministic and geostatistical approaches, the four most common methods in hydrological and soil studies [29,30], including Inverse Distance Weighting (IDW), spline, and kriging (simple and ordinary), were examined in the experimental site [31-33]. To select the most appropriate interpolation method for the EM38 readings, the IDW, spline, and kriging (simple and ordinary) techniques were compared [29,30,34-36]. The soil salinity map of Park 21 was developed from the EM38 readings using these four interpolation methods. Two common diagnostic statistics, namely the root-mean-square error (RMSE) and the standardized RMSE, were calculated to assess the accuracy of these interpolation approaches. The results showed IDW (Power 2) as the most appropriate interpolation method for this study.

A total of 23 topsoil samples were collected from Park 21 and were sent to the laboratory to validate the electrical conductivity readings from the EM38 survey. These 23 sampling points were randomly selected from two salinity zones delineated by ArcGIS techniques [1]. Because the salinity range of the soil was less than $2.2 \mathrm{dS} / \mathrm{m}$, which considers a low salinity range (non-saline), we limited salinity zoning into 2 zones of less than $1.2 \mathrm{dS} / \mathrm{m}$ and $1.2-2.2 \mathrm{dS} / \mathrm{m}$. The sampling points were positioned using a handheld GPS.

Standard methods were followed for sample preparation, packaging, labeling, and storage. Soil (Electrical Conductivity (EC) was measured in a 1:5 soil-to-water suspension after shaking and was adjusted based on the room temperature. To have a precise measurement, each sample was tested three times to report the average value.

To investigate the relationship between soil electrical conductivity values from the EM38 survey and destructive soil samples, a linear regression analysis was undertaken.

\subsection{Optical Remote Sensing}

Extensive research studies have been conducted over the last few decades to map soil salinity using remote sensing data from various sensors and platforms [11,37-41]. For this study, a recently launched advanced high-resolution satellite imagery of WorldView3 (WV3) acquired on 21 March 2015 was employed to assess the feasibility of soil salinity studies in urban vegetation. The WV3 provides the appropriate spatial resolution for urban mixed vegetation landscapes with spectral bands that previous studies have shown are suitable for salinity mapping [42]. This satellite image has eight multispectral bands in the near-infrared and visible spectra and eight bands in the shortwave infrared. This study is limited to the panchromatic and visible/near-infrared bands with spatial resolution of $0.31 \mathrm{~m}$ and $1.24 \mathrm{~m}$, respectively. These eight multispectral bands include coastal (B1, 400-450 nm), blue (B2, 450-510 nm), green (B3, 510-580 nm), yellow (B4, 585-625 nm), red (B5, 630-690 nm), red-edge 
(B6, 705-745 nm), near-IR1/NIR1 (B7, 770-895 nm), and near-IR2/NIR2 (B8, 860-1040 nm). The satellite imagery of WV3 presently has the highest spatial and spectral resolution among optical satellites.

Although the soil spectrum might be presumed uninflected, it can provide valuable information about soil properties. Several studies have investigated optimal spectral bands from airborne and space-borne sensors for mapping salt-affected areas [11,43]. The most common spectral indices-listed in Table 1-were extracted from a WV3 image of Park 21 using image processing and statistical techniques. This image has been cropped to only-vegetation pixels by hand-digitizing and has been pre-processed by the ordinary adjustments, such as atmospheric corrections, orthorectification, format conversion, masking, sun glint removal, and geo-referencing; these steps were described in detail by Nouri et al. [44].

Table 1. Spectral indices used for soil salinity modeling.

\begin{tabular}{|c|c|c|c|}
\hline & Indices & Equation & Ref. \\
\hline 1 & Normalized Differential Vegetation Index & $\mathrm{NDVI}=\left(\mathrm{B}_{4}-\mathrm{B}_{3}\right) /\left(\mathrm{B}_{4}+\mathrm{B}_{3}\right)$ & [45] \\
\hline 2 & Enhanced Vegetation Index & $\mathrm{EVI}=2.5 \times\left(\mathrm{B}_{4}-\mathrm{B}_{3}\right) /\left(\mathrm{B}_{4}+\left(\mathrm{C} 1 \times \mathrm{B}_{3}\right)-\left(\mathrm{C} 2 \times \mathrm{B}_{1}\right)+\mathrm{L}\right)$ & [46] \\
\hline 3 & Soil Adjusted Vegetation Index & $\mathrm{SAVI}=\left(\mathrm{B}_{4}-\mathrm{B}_{3}\right) \times(1+\mathrm{L}) /\left(\mathrm{B}_{4}+\mathrm{B}_{3}+\mathrm{L}\right)$ & [47] \\
\hline 4 & Ratio Vegetation Index & $\mathrm{RVI}=\mathrm{B}_{4} / \mathrm{B}_{3}$ & [48] \\
\hline 5 & Normalized Differential Salinity Index & $\mathrm{NDSI}=\left(\mathrm{B}_{3}-\mathrm{B}_{4}\right) /\left(\mathrm{B}_{3}+\mathrm{B}_{4}\right)$ & [49] \\
\hline 6 & Brightness Index & $\mathrm{BI}=\sqrt{\mathrm{B}_{2}^{2}+\mathrm{B}_{4}^{2}}$ & [50] \\
\hline 7 & Salinity Index & $\mathrm{SI}=\sqrt{\mathrm{B}_{1} \times \mathrm{B}_{3}}$ & [49] \\
\hline 8 & Salinity Index & SI1 $=\sqrt{B_{2} \times B_{3}}$ & [50] \\
\hline 9 & Salinity Index & $\mathrm{SI} 2=\sqrt{\mathrm{B}_{2}{ }^{2}+\mathrm{B}_{3}{ }^{2}+\mathrm{B}_{4}{ }^{2}}$ & [51] \\
\hline 10 & Salinity Index & $\mathrm{SI} 3=\sqrt{\mathrm{B}_{2}^{2}+\mathrm{B}_{3}^{2}}$ & [51] \\
\hline 11 & Salinity Index & SI_1 $1=B_{5} / B_{7}$ & [52] \\
\hline 12 & Salinity Index & SI_2 $=\left(B_{4}-B_{5}\right) /\left(B_{4}+B_{5}\right)$ & [52] \\
\hline 13 & Salinity Index & SI_3 $=\left(B_{5}-B_{7}\right) /\left(B_{5}+B_{7}\right)$ & [53] \\
\hline 14 & Soil Salinity and Sodicity Indices & SSSI- $1=\left(B_{5}-B_{7}\right)$ & [53] \\
\hline 15 & Soil Salinity and Sodicity Indices & SSSI- $2=\left(B_{5} \times B_{7}-B_{7} \times B_{7}\right) / B_{5}$ & [53] \\
\hline 16 & Salinity Index & $\mathrm{S} 1=\mathrm{B}_{1} / \mathrm{B}_{3}$ & [53] \\
\hline 17 & Salinity Index & $\mathrm{S} 2=\left(\mathrm{B}_{1}-\mathrm{B}_{3}\right) /\left(\mathrm{B}_{1}+\mathrm{B}_{3}\right)$ & [53] \\
\hline 18 & Salinity Index & $\mathrm{S} 3=\left(\mathrm{B}_{2} \times \mathrm{B}_{3}\right) / \mathrm{B}_{1}$ & [53] \\
\hline 19 & Salinity Index & $\mathrm{S} 5=\left(\mathrm{B}_{1} \times \mathrm{B}_{3}\right) / \mathrm{B}_{2}$ & [54] \\
\hline 20 & Salinity Index & $\mathrm{S} 6=\left(\mathrm{B}_{2} \times \mathrm{B}_{4}\right) / \mathrm{B}_{2}$ & [54] \\
\hline 21 & Salinity Index & ISK $=\left(\sqrt{\left(B_{3}-B_{2}\right) \times\left(B_{3}+B_{2}\right)}\right) /\left(\sqrt{\left.B_{3}^{2}+B_{2}^{2}\right)}\right.$ & [55] \\
\hline 22 & Salinity Index & $\begin{array}{c}\text { TSAVI }=\left(\mathrm{a} \times\left(\mathrm{B}_{4}-\left(\mathrm{a} \times \mathrm{B}_{3}+\mathrm{b}\right)\right) /\left(\mathrm{B}_{3}+\mathrm{a} \times\left(\mathrm{B}_{4}-\mathrm{b}\right)\right.\right. \\
+0.08\left(1+\mathrm{a}^{2}\right)\end{array}$ & [56] \\
\hline 23 & Perpendicular Vegetation Index & $\mathrm{PVI}=\left(\mathrm{B}_{4}-\left(\mathrm{a} \times \mathrm{B}_{3}+\mathrm{b}\right)\right) / \sqrt{1+\mathrm{a}^{2}}$ & [56] \\
\hline 24 & Salinity Index & Int1 $=\left(B_{2}+B_{3}\right) / 2$ & [57] \\
\hline 25 & Salinity Index & $\operatorname{Int} 2=\left(B_{2}+B_{3}+B_{4}\right) / 2$ & [57] \\
\hline 26 & Salinity Index & $\mathrm{WDVI}=\mathrm{B}_{4}-\mathrm{a} \times \mathrm{B}_{3}$ & [58] \\
\hline 27 & Salinity Index & $\mathrm{DVI}=\mathrm{B}_{4}-\mathrm{B}_{3}$ & [58] \\
\hline 28 & Salinity Index & Aster $_{\text {SI }}=($ SWIR1 - SWIR2 $) /($ SWIR1 + SWIR2 $)$ & [57] \\
\hline 29 & Salinity Index & $\mathrm{EC}=\mathrm{a}+\left(\frac{\mathrm{b} \times \mathrm{TM} 1+\mathrm{c} \times \mathrm{TM} 2+\mathrm{d} \times \mathrm{TM} 3+\mathrm{e} \times \mathrm{TM} 4}{\mathrm{f} \times \mathrm{TM} 4+\mathrm{g} \times \mathrm{TM} 7}\right)$ & [59] \\
\hline 30 & Salinity Index & SI $-11=$ SWIR $1 /$ SWIR 2 & [57] \\
\hline 31 & Normalized Difference Water Index & $\mathrm{NDWI}=\left(\mathrm{B}_{2}-\mathrm{B}_{5}\right) /\left(\mathrm{B}_{2}+\mathrm{B}_{5}\right)$ & [60] \\
\hline 32 & Simple Ratio Water Index & $\mathrm{SRWI}=\mathrm{B}_{3} 860 \mathrm{~nm} / \mathrm{B}_{3} 1240 \mathrm{~nm}$ & [61] \\
\hline 33 & Soil Surface Moisture & $\mathrm{SSM}=\left(\mathrm{B}_{6}-\mathrm{B}_{7}\right) /\left(\mathrm{B}_{6}+\mathrm{B}_{7}\right)$ & [62] \\
\hline 34 & Visible Atmospherically Resistant Index & VARI $=\left(B_{4}-B_{1}\right) /\left(B_{4}+B_{1}-B_{3}\right)$ & [63] \\
\hline 35 & Normalized Difference Infrared Index & $\mathrm{NDII}=\left(\mathrm{B}_{2}-\mathrm{B}_{6}\right) /\left(\mathrm{B}_{2}+\mathrm{B}_{6}\right)$ & [64] \\
\hline 36 & Aerosol-free Vegetation Index & AFRI1.6 $=\left(B_{N I R}-0.66 B_{1.6}\right) /\left(B_{N I R}+0.66 B_{1.6}\right)$ & [65] \\
\hline 37 & Aerosol-free Vegetation Index & AFRI2.1 $=\left(\mathrm{B}_{\mathrm{NIR}}-0.5 \mathrm{~B}_{2.1}\right) /\left(\mathrm{B}_{\mathrm{NIR}}+0.5 \mathrm{~B}_{2.1}\right)$ & [65] \\
\hline 38 & Land Surface Water Index & $\mathrm{LSWI}=(\mathrm{NIR}-\mathrm{SWIR}) /(\mathrm{NIR}+\mathrm{SWIR})$ & [66] \\
\hline 39 & Normalized Multi-band Drought Index & $\begin{array}{c}\mathrm{NDMI}=\left[\mathrm{B}_{3} 860 \mathrm{~nm}-\left(\mathrm{B}_{3} 1640 \mathrm{~nm}-\mathrm{B}_{3} 2130 \mathrm{~nm}\right)\right] / \\
{\left[\mathrm{B}_{3} 860 \mathrm{~nm}+\left(\mathrm{B}_{3} 1640 \mathrm{~nm}-\mathrm{B}_{3} 2130 \mathrm{~nm}\right]\right.}\end{array}$ & [67] \\
\hline 40 & Gypsic Index & $\left(\mathrm{B}_{5}-\mathrm{B}_{7}\right) /\left(\mathrm{B}_{5}+\mathrm{B}_{7}\right)$ & [68] \\
\hline 41 & Similarly Index & $\left(B_{5}-B_{4}\right) /\left(B_{5}+B_{4}\right)$ & [68] \\
\hline 42 & Salinity Index & $\left(\mathrm{B}_{4}-\mathrm{B}_{5}\right) /\left(\mathrm{B}_{4}+\mathrm{B}_{5}\right)$ & [69] \\
\hline 43 & Salinity Index & SI-1(2) $=\sqrt{\mathrm{B}_{2} \times \mathrm{B}_{3}}$ & [20] \\
\hline 44 & Salinity Index & SI-2(2) $=\sqrt{\mathrm{B}_{2}{ }^{2}+\mathrm{B}_{3}{ }^{2}+\mathrm{B}_{4}{ }^{2}}$ & [20] \\
\hline 45 & Salinity Index & $\mathrm{SI}-3(2)=\sqrt{\mathrm{B}_{2}^{2}+\mathrm{B}_{3}^{2}}$ & [20] \\
\hline
\end{tabular}


A set of eight variables (eight bands of WV3) were chosen as predictors of soil salinity. The remote sensing software ENVI was employed to extract values from all eight bands for each pixel from the WorldView3 image of Park 21.

Various spectral indices were calculated using two or more bands for differentiation between salinity features Nouri et al. [44].

\subsection{Modeling Soil Salinity Using Proximal and Remote Sensing Data}

Statistical exploration (data preparation and data analysis) was carried out to investigate the relationship between spectral indices driven from a high-resolution satellite image of WV3 together with a proximal sensing method of an EM38 survey.

The Stata 13 statistical package was employed for data analysis over 52,479 observations on 31 variables including 8 bands of WV3 and 23 salinity/vegetation indices. We excluded system errors, such as EM38 observations, which reported a negative value. The negative values were mainly recorded due to the presence of magnetic objects in the soil (e.g., lid of food cans). After these exclusions, our sample comprised at a total of 52,096 observations.

To assess the state of very high intercorrelations or inter-associations among the independent variables, a set of eight variables-eight multispectral bands of WV3-were assessed for data multicollinearity. The multicollinearity checked whether one predictor variable could be linearly predicted from other variables with a substantial degree of accuracy. From each pair of variables with extreme high correlations (>0.9), one was removed based on the previous literature to resolve the collinearity problem in the data. Mixed effect modeling was used to investigate the impact of random effects (e.g., location). The study area was divided into smaller zones defined by buffers, and mixed effects were tested and reported.

\section{Results and Discussion}

\subsection{Proximal Sensing and Laboratory}

The RMSE of the four interpolation methods of simple kriging, ordinary kriging, spline, and IDW (power 2) were found 20.8, 16.5, 14.7, and 14.2, respectively. Although there is not a large difference in the RMSE of the different methods, IDW (Power 2) showed the least error for this dataset. Figure 2 shows the salinity map of Park 21 using IDW (Power 2) as the interpolation method.

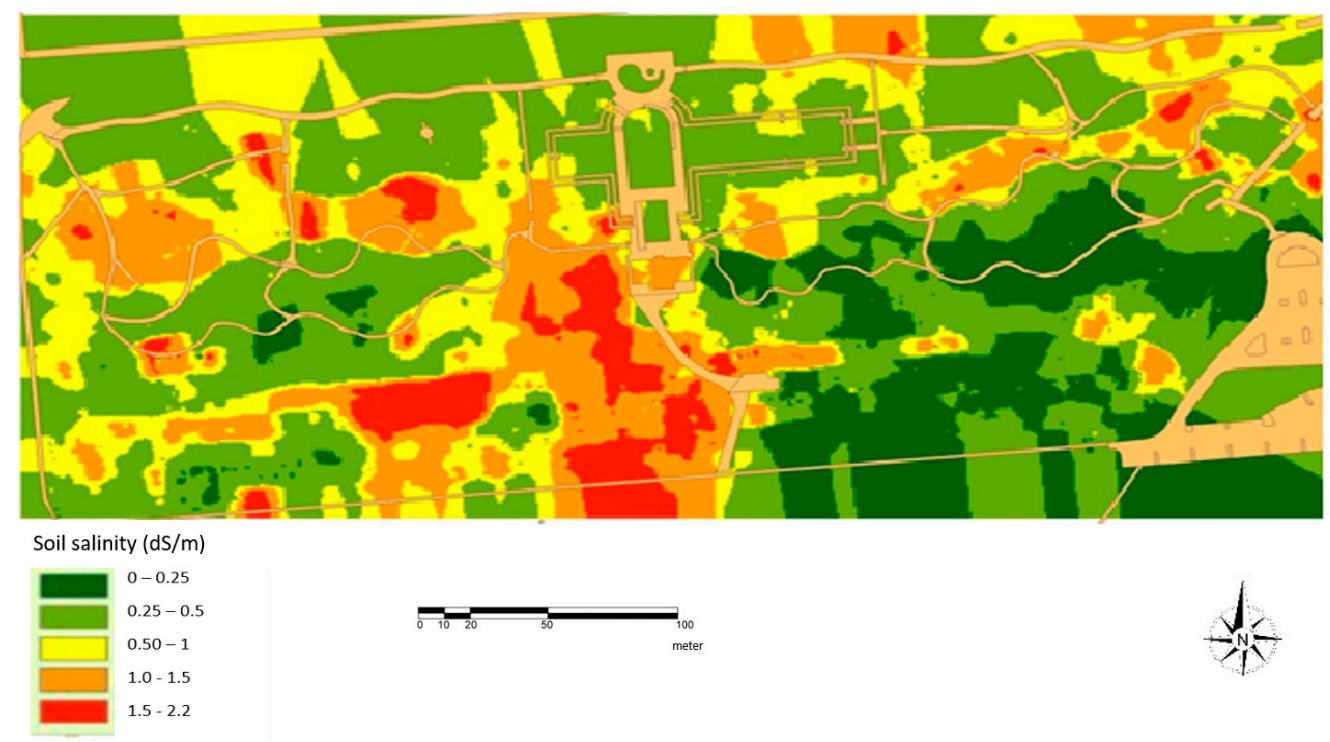

Figure 2. Salinity map of Park $21\left(34^{\circ} 56^{\prime} 24.5^{\prime \prime} \mathrm{S}, 138^{\circ} 36^{\prime} 08.3^{\prime \prime} \mathrm{E}\right)$ using the inverse distance weighting (IDW) (Power 2) interpolation method. 
The main statistical parameters for EC data, resulting from laboratory testing, are presented in Table 2. The EC values vary from $0.2 \mathrm{dS} / \mathrm{m}$ to $2.1 \mathrm{dS} / \mathrm{m}$, with an average of $0.54 \mathrm{dS} / \mathrm{m}$ and a median value of $0.4 \mathrm{dS} / \mathrm{m}$. Because the histogram is slightly skewed to the right, the mean value is slightly greater than the median.

Table 2. Descriptive statistics of laboratory EC measurements (dS/m).

\begin{tabular}{ccccccc}
\hline Mean & Median & Maximum & Minimum & SD-P & SD-S & CV (\%) \\
\hline 0.537 & 0.413 & 2.130 & 0.203 & 0.402 & 0.411 & 0.748 \\
\hline
\end{tabular}

Based on The Food and Agriculture Organization of the United Nations (FAO) soil salinity classes [70], the EC values of destructive soil samples were mainly in the non-saline category $(0-2 \mathrm{dS} / \mathrm{m})$. However, a relatively high coefficient of variations of $75 \%$ for the EC indicated a high variation in the measured salinity values in the limited non-saline range.

A correlation analysis between the laboratory results against the EM38 readings from the same coordinates in the field showed a positive correlation coefficient $(p<0.005 ; r=0.6343)$.

\subsection{Optical Remote Sensing}

Various spectral indices were calculated for each pixel. These calculations were applied to over 50,000 readings (Object ID) on the satellite image; a few of them are reported in Table 3.

Table 3. Spectral indices for different points.

\begin{tabular}{cccccc}
\hline OBJECT_ID & $\mathbf{1}$ & $\mathbf{2}$ & $\mathbf{3}$ & $\mathbf{4}$ & $\mathbf{5}$ \\
\hline EM38 & 22.1 & 21.9 & 20.9 & 19.9 & 20.4 \\
NDSI (R-NIR)/(R + NIR) & -0.677 & -0.677 & -0.677 & -0.656 & -0.656 \\
NDVI & 0.677 & 0.677 & 0.677 & 0.656 & 0.656 \\
EVI 2.5(NIR-red)/(NIR + 6red-7.5 blue + 1) & -3.08 & -3.08 & -3.08 & -3.198 & -3.198 \\
SAVI (NIR-R)/(NIR + R + L) (1 + L) & 0.501 & 0.501 & 0.501 & 0.485 & 0.485 \\
RVI (NIR/R) & 5.193 & 5.193 & 5.193 & 4.806 & 4.806 \\
BI (R2 + NIR2) $1 / 2$ & 602.876 & 602.876 & 602.876 & 608.763 & 608.763 \\
SI (blue $\times$ red) $1 / 2$ & 159.085 & 159.085 & 159.085 & 168.143 & 168.143 \\
SII (green $\times$ red)1/2 & 167.463 & 167.463 & 167.463 & 178.863 & 178.863 \\
SI2 (G2 + R2 + NIR2)1/2 & 651.134 & 651.134 & 651.134 & 661.178 & 661.178 \\
SI3 (G2 + R2)1/2 & 271.131 & 271.131 & 271.131 & 286.252 & 286.252 \\
S1 (blue/red) & 1.947 & 1.947 & 1.947 & 1.839 & 1.839 \\
S2 (blue-red)/(blue + red) & 0.321 & 0.321 & 0.321 & 0.295 & 0.295 \\
S3 (G $\times$ red)/blue & 126.324 & 126.324 & 126.324 & 140.316 & 140.316 \\
S4 (blue $\times$ red) $1 / 2$ & 102.878 & 102.878 & 102.878 & 109.581 & 109.581 \\
S5 (blue $\times$ red)/green & 102.878 & 102.878 & 102.878 & 109.581 & 109.581 \\
S6 (red $\times$ NIR)/green & 274.341 & 274.341 & 274.341 & 286.45 & 286.45 \\
DVI1 (NIR1-red) & 478 & 478 & 478 & 472 & 472 \\
DVI2 (NIR2-red) & 292 & 292 & 292 & 287 & 287 \\
DVI3 (NIR1-redEdge) & 286 & 286 & 286 & 283 & 283 \\
DVI4 (NIR2-redEdge) & 100 & 100 & 100 & 98 & 98 \\
GDVI1 (NIR1-green) & 346 & 346 & 346 & 338 & 338 \\
GDVI2 (NIR2-green) & 160 & 160 & 160 & 153 & 153 \\
\hline
\end{tabular}

\subsection{Modeling Soil Salinity Using Near and Remote Sensing Data}

The multicollinearity of eight bands from WV3 and EM38 were checked and reported in Table 4. 
Table 4. Correlation matrix of EM38 and predictors of soil salinity.

\begin{tabular}{cccccccccc}
\hline & EM38 & $\begin{array}{c}\text { B1 } \\
\text { Coastal }\end{array}$ & $\begin{array}{c}\text { B2 } \\
\text { Blue }\end{array}$ & $\begin{array}{c}\text { B3 } \\
\text { Green }\end{array}$ & $\begin{array}{c}\text { B4 } \\
\text { Yellow }\end{array}$ & $\begin{array}{c}\text { B5 } \\
\text { Red }\end{array}$ & $\begin{array}{c}\text { B6 } \\
\text { Red-Edge }\end{array}$ & $\begin{array}{c}\text { B7 } \\
\text { NIR1 }\end{array}$ & $\begin{array}{c}\text { B8 } \\
\text { NIR2 }\end{array}$ \\
\hline EM38 & 1 & & & & & & & & \\
B1Coastal & 0.0559 & 1 & & & & & & & \\
B2Blue & 0.0792 & 0.9463 & 1 & & & & & & \\
B3Green & 0.1043 & 0.8284 & 0.9163 & 1 & & & & \\
B4Yellow & 0.0865 & 0.8783 & 0.9467 & 0.9636 & 1 & & & \\
B5Red & 0.0607 & 0.8891 & 0.9555 & 0.9040 & 0.9647 & 1 & & 1 \\
B6Red-Edge & 0.0995 & 0.5384 & 0.6426 & 0.8576 & 0.7839 & 0.6508 & 1 & \\
B7NIR1 & 0.084 & 0.3899 & 0.4807 & 0.7327 & 0.6067 & 0.4595 & 0.9445 & 1 \\
B8NIR2 & 0.0805 & 0.3968 & 0.4911 & 0.737 & 0.6216 & 0.4728 & 0.9517 & 0.9797 & 1 \\
\hline
\end{tabular}

It was continued with B1 (coastal blue), B6 (red-edge), and B7 (NIR1) as the major predictor variables in the model. However, different combinations were also tested. Several regression models were fitted to the data to explore whether remote sensing can predict the salinity of the soil. Models were compared, and the best fit was chosen. It was started with simple linear regression as shown in Table 5 (Model 1).

Table 5. Linear regression of soil salinity, Model 1.

\begin{tabular}{ccc}
\hline EM38 & Coef. & $\boldsymbol{P}>\mathbf{z}$ \\
\hline B1 (Coastal Blue) & -0.07353 & 0.009 \\
B6 (Red-Edge) & 0.09696 & 0 \\
B7 (NIR1) & -0.02300 & 0 \\
-cons & 98.99310 & 0 \\
AIC & $573,957.7$ & \\
BIC & 574,002 & \\
\hline
\end{tabular}

Using the Stata 13 statistical package and mixed effect modeling, a robust model of salinity was fit to explore whether spectral indices from high-resolution satellite imagery can predict the soil salinity of urban landscape. Salinity was specified to be a function of a constant term and a set of covariates, which may be varying based on location (buffers). Unlike ordinary regression analysis of clustered data, mixed effect regression models do not assume that each observation is independent but do assume that data within clusters are dependent to some degree. The degree of this dependency is estimated along with the estimates of the usual model parameters, thus adjusting these effects for the dependency resulting from the clustering of the data.

In this study, we have considered the clustering of the data, at a location level by including buffers as random effect factors in the model to divide the area into smaller zones of similar characteristics. Random effects models handle a very general data structure, in which clusters can be of varying sizes and covariates can be specific to either the cluster or the individual observation, which is different from the ordinary regression analysis in which data would be aggregated at the observation level. For example, observations within areas near a creek might have similar characteristics to each other, while they are different from observations gathered from an area under the trees. We used mixed effect techniques to account for systematic observation-specific unobserved heterogeneity. In this model, we have a hierarchy of levels. At the top level, the units are 25 different areas of the park defined by buffers. At the lower level, we have repeated measurements of salinity in each of those areas. We expect that there are various measured and unmeasured aspects of the upper-level units that affect all of the lower-level measurements similarly for a given unit. Therefore, each area might have its own trend, and a separate linear regression could be fitted for that area through the introduction of random effects in the model. The results of this exploratory analysis are presented in Table 6 through Models $2-7$. Several combinations of the predictive variables were tested, and the significance of each variable 
was explored in various combinations. Care was taken not to include variables of high correlation with each other in the same model. The measures of relative quality and model selection of these models are also provided in order to choose the best fit for the data.

Table 6. Regression results for various models on EM38 by different levels of salinity.

\begin{tabular}{ccccccccccccc}
\hline & \multicolumn{2}{c}{ Model 2 } & \multicolumn{2}{c}{ Model 3 } & \multicolumn{2}{c}{ Model 4 } & \multicolumn{2}{c}{ Model 5 } & \multicolumn{2}{c}{ Model 6 } & \multicolumn{2}{c}{ Model 7 } \\
\hline EM38v & Coef. & $\boldsymbol{P}>\mathbf{z}$ & Coef. & $\boldsymbol{P}>\mathbf{z}$ & Coef. & $\boldsymbol{P}>\mathbf{z}$ & Coef. & $\boldsymbol{P}>\mathbf{z}$ & Coef. & $\boldsymbol{P}>\mathbf{z}$ & Coef. & $\boldsymbol{P}>\mathbf{z}$ \\
\hline B1 (Coastal Blue) & 0.6 & 0.283 & -0.3398 & 0.000 & 0.09947 & 0.062 & & & -0.3358 & 0 & -0.1099 & 0.021 \\
B6 (Red-Edge) & 0.11027 & 0.000 & 0.06795 & 0.000 & 0.14895 & 0.000 & & & 0.04417 & 0 & & \\
B7 (NIR1) & -0.0182 & 0.000 & & & & & 0.00882 & 0.000 & -0.0053 & 0.09 & 0.00714 & 0 \\
B3 (Green) & & & 0.05588 & 0.000 & & & & & 0.06524 & 0 & & \\
B4 (Yellow) & -0.0771 & 0.000 & & & -0.1078 & 0.000 & 0.25464 & 0.000 & & & 0.31922 & 0 \\
B8 (NIR2) & & & -0.0207 & 0.000 & -0.047 & 0.000 & & & & & & \\
B5 (Red) & & & & & & & -0.3262 & 0.000 & & & -0.2625 & 0 \\
B2 (Blue) & & & & & & & 0.18741 & 0.000 & & & & \\
_cons & 82.1058 & 0.000 & 137.835 & 0.000 & 76.4472 & 0.000 & 53.2329 & 0.000 & 136.2 & 0 & 99.3143 & 0 \\
AIC & 568,774 & & 568,749 & & 568,732 & & 568,668 & & 568,764 & & 568,708 & \\
BIC & 568,836 & & 568,811 & & 568,794 & & 568,731 & & 568,826 & & 568,770 & \\
\hline
\end{tabular}

However, before deciding on the best fit, the model was improved in one additional step for a better fit. At this stage, another random effect variable was added to the model to account for the variety in soil salinity. In this case, the salinity level of the soil was divided into 4 groups of less than $0.5,0.5-1.2,1.2-2.0$, and over 2.0 for EM38. The results of this set of analyses are presented in Table 7 through Models 8-13.

Table 7. Regression results for various models on EM38 by different levels of salinity.

\begin{tabular}{cllllllllllll}
\hline & \multicolumn{2}{c}{ Model 8 } & \multicolumn{2}{c}{ Model 9 } & \multicolumn{2}{c}{ Model 10 } & \multicolumn{2}{c}{ Model 11 } & \multicolumn{2}{c}{ Model 12 } & \multicolumn{2}{c}{ Model 13 } \\
\hline EM38v & Coef. & $\boldsymbol{P}>\mathbf{z}$ & Coef. & $\boldsymbol{P}>\mathbf{z}$ & Coef. & $\boldsymbol{P}>\mathbf{z}$ & Coef. & $\boldsymbol{P}>\mathbf{z}$ & Coef. & $\boldsymbol{P}>\mathbf{z}$ & Coef. & $\boldsymbol{P}>\mathbf{z}$ \\
\hline B1 (Coastal Blue) & 0.059 & 0.009 & -0.107 & 0.000 & -0.115 & 0.000 & 0.039 & 0.078 & -0.039 & 0.046 & \\
B6 (Red-Edge) & 0.055 & 0.000 & 0.028 & 0.000 & 0.025 & 0.000 & 0.055 & 0.000 & & & \\
B7 (NIR1) & -0.021 & 0.000 & & & -0.014 & & & & -0.007 & 0.000 & -0.007 & 0.000 \\
B3 (Green) & & & 0.023 & 0.000 & 0.026 & 0.000 & & & & & & \\
B4 (Yellow) & -0.037 & 0.000 & & & & & -0.031 & 0.000 & 0.139 & 0.000 & 0.134 & 0.000 \\
B8 (NIR2) & & & -0.022 & 0.000 & & 0.000 & -0.030 & 0.000 & & & & \\
B5 (Red) & & & & & & & & & -0.107 & 0.000 & -0.109 & 0.000 \\
B2 (Blue) & & & & & & & & & & & -0.005 & 0.694 \\
cons & 120.474 & 0.003 & 143.394 & 0.000 & 144.611 & 0.000 & 123.262 & 0.002 & 131.745 & 0.001 & 126.268 & 0.002 \\
AIC & 478,380 & & 478,386 & & 478,378 & & 478,387 & & 478,362 & & 478,366 \\
BIC & 478,442 & & 478,448 & & 478,440 & & 478,450 & & 478,424 & & 478,428 & \\
\hline
\end{tabular}

All models are compared based on the Akaike information criterion (AIC) and Bayesian information criterion (BIC) measures (The Akaike information criterion (AIC) is a measure of the relative quality of statistical models for a given set of data. Given a collection of models for the data, AIC estimates the quality of each model, relative to each of the other models. Hence, AIC provides a means for model selection. The Bayesian information criterion (BIC) is a criterion for model selection among a finite set of models, and the model with the lowest BIC is preferred. It is based, in part, on the likelihood function and it is closely related to the AIC.). Model 12 shows the smallest combination of AIC and BIC; therefore, it is the best of the 13 different models. This model suggests that EM38v can be explained by a range of variables including B1(coastal blue), B7(NIR1), B4(yellow), and B5(red) at a significance level of 0.05 . The model can be used in further research to predict/estimate EM38v based on the variables stated as significant in this model. Table 6 shows the regression results for various models on EM38 by different location buffers.

In Table 8, EM38 is reflected as the dependent variable and EVI and SAVI as the predictor variables. A set of derived variables used in other research papers, such as NDVI, SI, NDSI, and GDVI, were also 
checked as possible predictors; no variable except SAVI was found to be a significant predictor of soil salinity. Here, only EVI was reported as an example.

Table 8. Mixed effect modeling of soil salinity based on derived variables.

\begin{tabular}{cccccc}
\hline EM38 & Coef. & Std. Err. & $\begin{array}{c}\mathbf{z} \\
\boldsymbol{P}>\mathbf{z}\end{array}$ & [95\% Conf. & Interval] \\
\hline \multirow{2}{*}{ EVI } & \multirow{2}{*}{0.0004198} & 0.001419 & $\begin{array}{c}0.30 \\
0.767\end{array}$ & -0.00236 & 0.003202 \\
\hline \multirow{2}{*}{ SAVI } & \multirow{2}{*}{45.82032} & \multirow{2}{*}{2.641757} & $\begin{array}{l}17.34 \\
0.000\end{array}$ & 40.64257 & 50.99807 \\
\hline \multirow{2}{*}{ Cons } & \multirow{2}{*}{83.14401} & \multirow{2}{*}{5.576818} & $\begin{array}{l}14.91 \\
0.000\end{array}$ & 72.21364 & 94.07437 \\
\hline
\end{tabular}

The last variable (_cons) represents the constant or intercept. Coef. are the values for the regression equation for predicting the dependent variable of EVI and SAVI from EM38. Std. Err. is the standard error associated with the coefficient. The z-statistic value tested whether a given coefficient is significantly different from zero and $\mathrm{P}>\mathrm{z}$ shows the two-tailed $p$-values used in testing the null hypothesis if the coefficient is equal to zero. The results show that the very small coefficient of EVI is not statistically significant at the 0.05 level, because the $p$-value is greater than 0.05 , while the large coefficient of SAVI is statistically significant, because its $p$-value of 0.000 is less than 0.05 . This confirms that "SAVI" can be considered as a predictor for EM38.

\section{Conclusions and Recommendations}

The potential risk of salt leaching through wastewater irrigation is of concern for most local governments and city councils. The availability of proximal and remote sensing technologies and spatial and geostatistical models enabled the prediction of soil properties at different spatial and temporal scales. This study investigated the capability and feasibility of predicting the soil salinity status for urban greenery in a semi-arid climate using the two approaches of proximal sensing and remote sensing.

A mobile EM38 electromagnetic sensing system was employed to obtain soil electrical conductivity information for a series of 52,096 sampling points in an urban park in Adelaide in South Australia (Park 21 within the Adelaide Parklands). The data obtained from the EM38 survey were verified with laboratory data from destructive soil samples taken from the experimental site. The advanced high-resolution satellite of WorldView3 was selected to assess soil salinity of this urban park using optical remote sensing. A total of 23 different spectral indices-the most common vegetation and salinity indices-were extracted from eight different spectral bands of a WorldView3 image. Of all the spectral indices that were extracted from the WV3 image, only SAVI showed a moderate correlation of EM38 values. This means that the SAVI index extracted from the high-resolution multispectral WV3 image could be considered as a predictor for soil salinity.

Our results found proximal sensing to be a more practical and feasible predictor of soil salinity in urban greenery compared with a high-spatial resolution image of optical remote sensing in this study area, but further investigation is required.

Author Contributions: Conceptualization, H.N.; Methodology, H.N.; Software, H.N. and S.J.A.; Validation, H.N., S.J.A., S.A. and S.C.B.; Formal Analysis, H.N., S.C.B. and S.P.; Investigation, H.N., S.C.B. and S.A.; Resources, H.N., S.C.B., S.J.A. and P.S.; Data Curation, H.N., S.C.B., S.A. and S.P.; Writing-Original Draft Preparation, H.N. and S.C.B.; Writing-Review \& Editing, H.N., S.C.B., S.A., and S.P.; Supervision, P.S. and S.B.; Project Administration, H.N.; Funding Acquisition, H.N., S.J.A., P.S. and S.B.

Funding: This study was funded by the South Australia Water Corporation through research grant SW100. 
Acknowledgments: The authors appreciate the support of Greg Ingleton in from SA Water and Kent Williams in the Adelaide City Council. The authors are very grateful for the assistance of Marzieh Khedri and technical staff from the School of Natural and Built Environments at the University of South Australia. The authors also appreciate the advice of John Boland, Jim Hill from the University of South Australia, and Terry Evans from Ground-Spec Pty. Ltd.

Conflicts of Interest: The authors declare no conflicts of interest.

\section{References}

1. Nouri, H.; Beecham, S.; Hassanli, A.M.; Ingleton, G. Variability of drainage and solute leaching in heterogeneous urban vegetation environs. Hydrol. Earth Syst. Sci. 2013, 17, 4339-4347. [CrossRef]

2. Aimrun, W.; Amin, M.S.M.; Nouri, H. Paddy Field Zone Characterization using Apparent Electrical Conductivity for Rice Precision Farming. Int. J. Agric. Res. 2011, 1, 10-28. [CrossRef]

3. Scudiero, E.; Corwin, D.L.; Morari, F.; Anderson, R.G.; Skaggs, T.H. Spatial interpolation quality assessment for soil sensor transect datasets. Comput. Electron. Agric. 2016, 123, 74-79. [CrossRef]

4. Saleh, A.A.-H. Remote Sensing of Soil Salinity in an Arid Areas in Saudi Arabia. Int. J. Civ. Environ. Eng. 2010, 10, 12-17.

5. Alizade Govarchin Ghale, Y.; Baykara, M.; Unal, A. Analysis of decadal land cover changes and salinization in Urmia Lake Basin using remote sensing techniques. Nat. Hazards Earth Syst. Sci. Discuss. 2017, 2017, 1-15. [CrossRef]

6. Khan, N.M.; Rastoskuev, V.V.; Shalina, E.V.; Sato, Y. Mapping salt-affected soils using remote sensing indicators-A simple approach with the use of GIS IDRIS. In Proceedings of the 22nd Asian Conference on Remote Sensing, Singapore, 5-9 November 2001.

7. Whitney, K.; Scudiero, E.; El-Askary, H.M.; Skaggs, T.H.; Allali, M.; Corwin, D.L. Validating the use of MODIS time series for salinity assessment over agricultural soils in California, USA. Ecol. Indic. 2018, 93, 889-898. [CrossRef]

8. Dehni, A.; Lounis, M. Remote Sensing Techniques for Salt Affected Soil Mapping: Application to the Oran Region of Algeria. Procedia Eng. 2012, 33, 188-198. [CrossRef]

9. Alexakis, D.D.; Daliakopoulos, I.N.; Panagea, I.S.; Tsanis, I.K. Assessing soil salinity using WorldView-2 multispectral images in Timpaki, Crete, Greece. Geocarto Int. 2018, 33, 321-338. [CrossRef]

10. Long, M. A Biodiversity Survey of the Adelaide Park Lands, South Australia in 2003; Department for Environment and Heritage: Adelaide, South Australia, Australia, 2003.

11. Metternicht, G.; Zinck, A. Remote Sensing of Soil Salinization: Impact on Land Management; CRC Press: Boca Raton, FL, USA, 2008.

12. Hengl, T. A Practical Guide to Geostatistical Mapping of Environmental Variables; Institute for Environment and Sustainability, European Commission-Joint Research Centre: Ispra, Italy, 2007.

13. Ding, J.; Yu, D. Monitoring and evaluating spatial variability of soil salinity in dry and wet seasons in the Werigan-Kuqa Oasis, China, using remote sensing and electromagnetic induction instruments. Geoderma 2014, 235-236, 316-322. [CrossRef]

14. Heil, K.; Schmidhalter, U. Comparison of the EM38 and EM38-MK2 electromagnetic induction-based sensors for spatial soil analysis at field scale. Comput. Electron. Agric. 2015, 110, 267-280. [CrossRef]

15. Li, H.Y.; Shi, Z.; Webster, R.; Triantafilis, J. Mapping the three-dimensional variation of soil salinity in a rice-paddy soil. Geoderma 2013, 195-196, 31-41. [CrossRef]

16. Lesch, S.M.; Rhoades, J.D.; Herrero, J. Monitoring for Temporal Changes in Soil Salinity using Electromagnetic Induction Techniques. Soil Sci. Soc. Am. J. 1998, 62, 232-242. [CrossRef]

17. Li, X.-M.; Yang, J.-S.; Liu, M.-X.; Liu, G.-M.; Yu, M. Spatio-Temporal Changes of Soil Salinity in Arid Areas of South Xinjiang Using Electromagnetic Induction. J. Integr. Agric. 2012, 11, 1365-1376. [CrossRef]

18. Yao, R.; Yang, J. Quantitative evaluation of soil salinity and its spatial distribution using electromagnetic induction method. Agric. Water Manag. 2010, 97, 1961-1970. [CrossRef]

19. Zheng, Z.; Zhang, F.R.; Ma, F.Y.; Chai, X.R.; Zhu, Z.Q.; Shi, J.L.; Zhang, S.X. Spatiotemporal changes in soil salinity in a drip-irrigated field. Geoderma 2009, 149, 243-248. [CrossRef]

20. Brevik, E.; Fenton, T.; Lazari, A. Soil electrical conductivity as a function of soil water content and implications for soil mapping. Precis. Agric 2006, 7, 393-404. [CrossRef] 
21. Geonics Limited. EM38 Ground Conductivity Meter Operating Manual; Geonics Limited: Mississauga, ON, Canada, 2002.

22. Doolittle, J.A.; Brevik, E.C. The use of electromagnetic induction techniques in soils studies. Geoderma 2014, 223-225, 33-45. [CrossRef]

23. Scudiero, E.; Skaggs, T.H.; Corwin, D.L. Regional-scale soil salinity assessment using Landsat ETM + canopy reflectance. Remote. Sens. Environ. 2015, 169, 335-343. [CrossRef]

24. Brevik, E.C. Analysis of the Representation of Soil Map Units using a Common Apparent Electrical Conductivity Sampling Design for the Mapping of Soil Properties. Soil Horiz. 2012, 53, 32-37. [CrossRef]

25. Bhunia, G.S.; Shit, P.K.; Maiti, R. Comparison of GIS-based interpolation methods for spatial distribution of soil organic carbon (SOC). J. Saudi Soc. Agric. Sci. 2016. [CrossRef]

26. Gong, G.; Mattevada, S.; O'Bryant, S.E. Comparison of the accuracy of kriging and IDW interpolations in estimating groundwater arsenic concentrations in Texas. Environ. Res. 2014, 130, 59-69. [CrossRef] [PubMed]

27. Xie, Y.; Chen, T.-B.; Lei, M.; Yang, J.; Guo, Q.-J.; Song, B.; Zhou, X.-Y. Spatial distribution of soil heavy metal pollution estimated by different interpolation methods: Accuracy and uncertainty analysis. Chemosphere 2011, 82, 468-476. [CrossRef] [PubMed]

28. Zhu, Q.; Lin, H.S. Comparing Ordinary Kriging and Regression Kriging for Soil Properties in Contrasting Landscapes. Pedosphere 2010, 20, 594-606. [CrossRef]

29. Cook, R.A.; Mostaghimi, S.; Campbell, J.B. Assessment of methods for interpolating steady-state infiltration. Trans. ASAE 1993, 36, 1241-1333.

30. Gumiere, S.J.; Lafond, J.A.; Hallema, D.W.; Périard, Y.; Caron, J.; Gallichand, J. Mapping soil hydraulic conductivity and matric potential for water management of cranberry: Characterisation and spatial interpolation methods. Biosyst. Eng. 2014, 128, 29-40. [CrossRef]

31. Neely, H.L.; Morgan, C.L.S.; Hallmark, C.T.; McInnes, K.J.; Molling, C.C. Apparent electrical conductivity response to spatially variable vertisol properties. Geoderma 2016, 263, 168-175. [CrossRef]

32. Piikki, K.; Söderström, M.; Stenberg, B. Sensor data fusion for topsoil clay mapping. Geoderma 2013, 199, 106-116. [CrossRef]

33. Rodrigues, F.A.; Bramley, R.G.V.; Gobbett, D.L. Proximal soil sensing for Precision Agriculture: Simultaneous use of electromagnetic induction and gamma radiometrics in contrasting soils. Geoderma 2015, 243-244, 183-195. [CrossRef]

34. Anderson, S. An Evaluation of Spatial Interpolation Methods on Air Temperature in Phoenix, AZ. 2002. Available online: http://www.cobblestoneconcepts.com/ucgis2summer/anderson/anderson.htm (accessed on 15 February 2016).

35. Eldeiry, A.; García, L. Using Deterministic and Geostatistical Techniques to Estimate Soil Salinity at the Sub-Basin Scale and the Field Scale. In Proceedings of the 31th Annual Hydrology Days, Fort Collins, CO, USA, 21-23 March 2011.

36. Urquhart, E.A.; Hoffman, M.J.; Murphy, R.R.; Zaitchik, B.F. Geospatial interpolation of MODIS-derived salinity and temperature in the Chesapeake Bay. Remote. Sens. Environ. 2013, 135, 167-177. [CrossRef]

37. Allbed, A.; Kumar, L. Soil Salinity Mapping and Monitoring in Arid and Semi-Arid Regions Using Remote Sensing Technology: A Review. Adv. Remote Sens. 2013, 2, 373. [CrossRef]

38. Asadzadeh, S.; de Souza Filho, C.R. Investigating the capability of WorldView-3 superspectral data for direct hydrocarbon detection. Remote Sens. Environ. 2016, 173, 162-173. [CrossRef]

39. Gorji, T.; Tanik, A.; Sertel, E. Soil Salinity Prediction, Monitoring and Mapping Using Modern Technologies. Procedia Earth Planet. Sci. 2015, 15, 507-512. [CrossRef]

40. Metternicht, G.I.; Zinck, J.A. Remote sensing of soil salinity: Potentials and constraints. Remote Sens. Environ. 2003, 85, 1-20. [CrossRef]

41. Pu, R.; Landry, S. A comparative analysis of high spatial resolution IKONOS and WorldView-2 imagery for mapping urban tree species. Remote Sens. Environ. 2012, 124, 516-533. [CrossRef]

42. Kruse, F.A.; Baugh, W.M.; Perry, S.L. Validation of DigitalGlobe WorldView-3 Earth imaging satellite shortwave infrared bands for mineral mapping. J. Appl. Remote Sens. 2015, 9, 096044. [CrossRef]

43. Taylor, G.R.; Mah, A.H.; Kruse, F.A.; Kierein-Young, K.S.; Hewson, R.D.; Bennett, B.A. Characterization of saline soils using airborne radar imagery. Remote Sens. Environ. 1996, 57, 127-142. [CrossRef]

44. Nouri, H.; Greg, I.; Beecham, S.; Anderson, S. Remotely-Sensed Modelling of Soil Salinity from WasteWater Irrigation in the Adelaide Parklands; SA Water: Adelaide, South Australia, Australia, 2016. 
45. Rouse, J.W.; Hass, R.H.; Schell, J.A.; Deering, D.W. Monitoring vegetation systems in the Great Plains with ERTS. In Proceedings of the Third ERTS Symposium, Washington, DC, USA, 10-14 December 1973; pp. 309-317.

46. Liu, H.Q.; Huete, A.R. A feedback based modification of the NDV I to minimize canopy background and atmospheric noise. IEEE Trans. Geosci. Remote Sens. 1995, 33, 457-465.

47. Huete, A.R. A soil-adjusted vegetation index (SAVI). Remote. Sens. Environ. 1988, 25, 295-309. [CrossRef]

48. Pearson, R.L.; Miller, L.D. Remote mapping of standing crop biomass for estimation of the productivity of the short-grass Prairie, Pawnee National Grasslands Colorado. In Proceedings of the Eighth International Symposium on Remote Sensing of Environment, Ann Arbor, MI, USA, 2-6 October 1976; Willow Run Laboratories, Environmental Research Institute of Michigan: Ann Arbor, MI, USA, 1972; pp. 1357-1381.

49. Tripathi, N.K.; Rai, B.K.; Dwivedi, P. Spatial Modeling of Soil Alkalinity in GIS Environment Using IRS data. In Proceedings of the 18th Asian Conference on Remote Sensing, Kuala Lumpur, Malaysia, 20-25 October 1997; pp. A.8.1-A.8.6.

50. Khan, N.M.; Rastoskuev, V.V.; Sato, Y.; Shiozawa, S. Assessment of hydrosaline land degradation by using a simple approach of remote sensing indicators. Agric. Water Manag. 2005, 77, 96-109. [CrossRef]

51. Douaoui, A.E.K.; Nicolas, H.; Walter, C. Detecting salinity hazards within a semiarid context by means of combining soil and remote-sensing data. Geoderma 2006, 134, 217-230. [CrossRef]

52. IDNP. Indo-Dutch Network Project: A Methodology for Identification of Waterlogging and Soil Salinity Conditions Using Remote Sensing; IDNP: Karnal, India, 2003.

53. Bannari, A.; Guedon, A.M.; El-Harti, A.; Cherkaoui, F.Z.; El-Ghmari, A. Characterization of Slightly and Moderately Saline and Sodic Soils in Irrigated Agricultural Land using Simulated Data of Advanced Land Imaging (EO-1) Sensor. Commun. Soil Sci. Plant Anal. 2008, 39, 2795-2811. [CrossRef]

54. Abbas, A.; Khan, S. Using Remote Sensing Techniques for Appraisal of Irrigated Soil Salinity. In Proceedings of the International Congress on Modelling and Simulation (MODSIM), Christchurch, New Zealand, 10-13 December 2007; pp. 2632-2638. Available online: https: / www.mssanz.org.au/MODSIM07/papers / 46_s60/UsingRemotes60_Abbas_.pdf (accessed on 4 April 2018).

55. Noureddine, K.; Eddine, M.D.; Kader, D.A.E. New Index for Salinity Assessment Applied on Saline Context Area (Case of the Lower Chiff Plain). Int. J. Sci. Basic Appl. Res. 2014, 18, 401-404.

56. Baret, F.; Guyot, G.; Major, D.J. TSAVI: A vegetation index which minimizes soil brightness effects on LAI and APAR estimation. In Proceedings of the Geoscience and Remote Sensing Symposium-IGARSS'89/12th International Canadian Symposium on Remote Sensing, Vancouver, BC, Canada, 10-14 July 1989; IEEE: New York, NY, USA, 1989; pp. 1355-1358.

57. Bouaziz, M.; Matschullat, J.; Gloaguen, R. Improved remote sensing detection of soil salinity from a semi-arid climate in Northeast Brazil. C. R. Geosci. 2011, 343, 795-803. [CrossRef]

58. Basso, F.; Bove, E.; Dumontet, S.; Ferrara, A.; Pisante, M.; Quaranta, G.; Taberner, M. Evaluating environmental sensitivity at the basin scale through the use of geographic information systems and remotely sensed data: An example covering the Agri basin (Southern Italy). Catena 2000, 40, 19-35. [CrossRef]

59. Ekercin, S.; Ormeci, C. Estimating Soil Salinity Using Satellite Remote Sensing Data and Real-Time Field Sampling. Environ. Eng. Sci. 2008, 25, 981-988. [CrossRef]

60. Yu, C.; Fu, C.; Huo, L.Q. The feasibility study of soil moisture monitoring based on MODIS data under different vegetation coverage. J. Remote Sens. 2006, 10, 783-788.

61. Zarco-Tejada, P.J.; Rueda, C.A.; Ustin, S.L. Water content estimation in vegetation with MODIS reflectance data and model inversion methods. Remote Sensing of Environment. Remote Sens. Environ. 2003, 85, 109-124. [CrossRef]

62. Lovejoy, S.; Schertzer, D.; Allaire, V.C. The remarkable wide range spatial scaling of TRMM precipitation. Atmos. Res. 2008, 90, 10-32. [CrossRef]

63. Stow, D.; Niphadkar, M.; Kaiser, J. MODIS-derived visible atmospherically resistant index for monitoring chaparral moisture content. Int. J. Remote Sens. 2005, 26, 3867-3873. [CrossRef]

64. Hardisky, M.A.; Klemas, V.; Smart, R.M. The influence of soil salinity, growth form, and leaf moisture on the spectral radiance of spartinaalterniora canopies. Hotogramm. Eng. Remote Sens. 1983, 49, 77-83.

65. Karnieli, A.; Kaufman, Y.J.; Remer, L.; Wald, A. AFRI-Aerosol free vegetation index. Remote Sens. Environ. 2001, 77, 10-21. [CrossRef] 
66. Xiao, X.; Zhang, Q.; Saleska, S.; Hutyra, L.; De Camargo, P.; Wofsy, S.; Frolking, S.; Boles, S.; Keller, M.; Moore, B. Satellite-based modeling of gross primary production in a seasonally moist tropical evergreen forest. Remote Sens. Environ. 2005, 94, 105-122. [CrossRef]

67. Wang, L.; Qu, J. NMDI: A normalized multi-band drought index for monitoring soil and vegetation moisture with satellite remote sensing. Geophys. Res. Lett. 2007, 34. [CrossRef]

68. Nield, S.J.; Boettinger, J.L.; Ramsey, R.D. Digitally Mapping Gypsic and Natric Soil Areas Using Landsat ETM Data Abbreviations: DEM, digital elevation model; NDVI, normalized difference vegetation index; NIR, near infrared; OIF, optimum index factor; SWIR, shortwave infrared. Soil Sci. Soc. Am. J. 2007, 71, 245-252. [CrossRef]

69. Ding, J.-L.; Wu, M.-C.; Tiyip, T. Study on Soil Salinization Information in Arid Region Using Remote Sensing Technique. Agric. Sci. China 2011, 10, 404-411. [CrossRef]

70. Abrol, P.; Yadav, J.S.P.; Massoud, F.I. Salt-Affected Soils and Their Management; FAO Soil Resources Management and Conservation Service: Rome, Italy, 1998.

(C) 2018 by the authors. Licensee MDPI, Basel, Switzerland. This article is an open access article distributed under the terms and conditions of the Creative Commons Attribution (CC BY) license (http:// creativecommons.org/licenses/by/4.0/). 